\title{
The partial reinforcement effect after minimal acquisition: Single pellet reward'
}

GARVIN MCCAIN, University of Texas at Aringtom. Arlington, Tex. $760(10)$

Achievement for a PREE following a small number of acquisition trials has posed a problem for several explanations of the PREE. One explanation of the effects achiered with minimal acquisition assumes Ss make maltiple responses on each trial due to the ase of multiple pellets or wet mash. A partial and a consistent group) were run, using a single pellet as reward. The usual PREE was achieved.

Over the past few years a substantial number of studies employing a very limited number of aceuisition trials have been run (Mccain, 1960; Spence, Platt, \& Matsumoto, 1965; (apildi \& Deutsch, 1967: Padilla, 1967). Such studies raise serious questions concerning what Capaldi \& Deutsch (1967) have called the "threshold concept." The central problem is whether a very limited number of acquisition trials are sufficient to produce a PREE or other effects typically found in situations involving a moderate or extensive number of acquisition trials.

One of the more important systems of constructs based on a threshold concept is the frustration hypothesis (Amsel, 1958). In an earlier study Amsel and his coinvestigators (Surridge, Rashotte, \& Amsel, 1967) failed to find a PREE following either four acquisition trials or 24 pretraining trials followed by four acquisition trials. More recently, Amsel, Hug \& Surridge (1968) did find a PREE with either 10- or 20-pellet reward per trial and five acquisition trials, but failed to find a PREE with either one or two pellets. These later results were interpreted as indicating a rapid conditioning of $r_{R}$, presumably due to multiple responses by the Ss when several pellets were used as reward on each trial.

As indicated in the Discussion section, there are studies which are difficult to explain even if the multiple response hypothesis is accepted. However, a mort direct approach to the problem is to determine whether a PREE can be achieved following a very limited number of acquisition trials employing a single pellet as a reward.

\section{METHOD}

\section{Subjects and Apparatus}

The Ss were 42 Long Evans rats from the University of Texas at Arlington colony. All Ss were approximately 110 days old at the beginning of the experiment. The apparatus was a straight alley approximately $6 \mathrm{ft}$ long (including start and goal boxes), $3 \frac{1}{4}$ in. wide, and 4 in. deep. Four time measures were taken. A full-alley time began when the start box (SB) door was opened and ended when the $S$ passed a photoelectric cell approximately 4 in. from the goal cup. Other measures were: Run 1, a 12-in. section beginning 12-in. from the SB door; Run 2, an 18-in. section beginning at the termination of the Run 1 section; Goal, a 12-in. section beginning at the termination of the Run 2 section and ending approximately 4 in. from the goal cup.

\section{PROCEDURE}

On Day 1 a 23-h deprivation schedule was started. Days 2-6 Ss were handled for $1 \mathrm{~h}$ daily, with lab pellets available on the handling table. Days 7-12 Ss explored the maze in groups of three; approximately $15 \mathrm{~min}$ after exploration Ss were fed lab pellets for $1 \mathrm{~h}$. In addition to exploration, on Days 9-12 Ss were fed one 500-mg Noyes pellet approximately $15 \mathrm{~min}$ before exploration began. Ss were assigned to cages on a random basis after exploration on Day 12. Cage assignment determined group assignment. An ABBA running order was used for Ss from the two groups. Acepuisition and extinction Irials were given on 1)ay 13 . Fach $S$ received six acquisition and 10 extinction trials. Ss in (iroup P were given a NRNRNR reinforcement pattern while $S$ s in (iroup ( were reinforced on each acquisition trial. On reinforeed trials $S s$ were allowed to eat a single $500-\mathrm{mg}$ Noyes pellet. On all trials $S$ s were placed in the SB and when facing the door, it was raised. Ss were allowed $40 \mathrm{sec}$ to reach the $\mathrm{CB}$ and were guided after that time. Any $S$ failing to reach the $G B$ within $40 \mathrm{sec}$ on any two acquisition trials, including the first extinction trial, was dropped. Seven Ss were dropped from Group $C$ and four from Group $P$. There was a 15 -sec intertrial interval between all trials. In extinction, Ss failing to reach the $G B$ within $40 \mathrm{sec}$ were guided and given a score of $10 \mathrm{sec}$ in each section of the nunway unless they had registered a shorter time. Ss were confined to the GB for 15 sec on all nonreinforced trials.

\section{RESULTS AND DISCUSSION}

There were no significant differences in Run 1, Run 2, or Full-alley times during acquisition, although Group $C$ ran faster in each section. Group $C$ did run significantly faster in the goal section $(F=5.69, \mathrm{df}=1 / 29 ; p<.025)$.

In Fig. 1 the run times from three sections of the alley together with the full-alley time are plotted for the extinction phase. The groups do differ in resistance to extinction in each analysis with Group $P$ more resistant. With $\mathrm{df}=1 / 29$ in each case, the results are: Run 1, $F=8.70, p<.01 ;$ Run 2, $\mathrm{F}=6.14, \mathrm{p}<.02 ;$ Goal, $\mathrm{F}=10.60, \mathrm{p}<.005 ;$ Full-alley, $F=9.29, p<.005$. Group $P$ ran faster than Group $C$ on Extinction Trial 1 in the Run 1 measure, but the order was reversed in the Run 2, Goal, and Full-alley times. The clear conclusion is that Group $P$ was more resistant to extinction

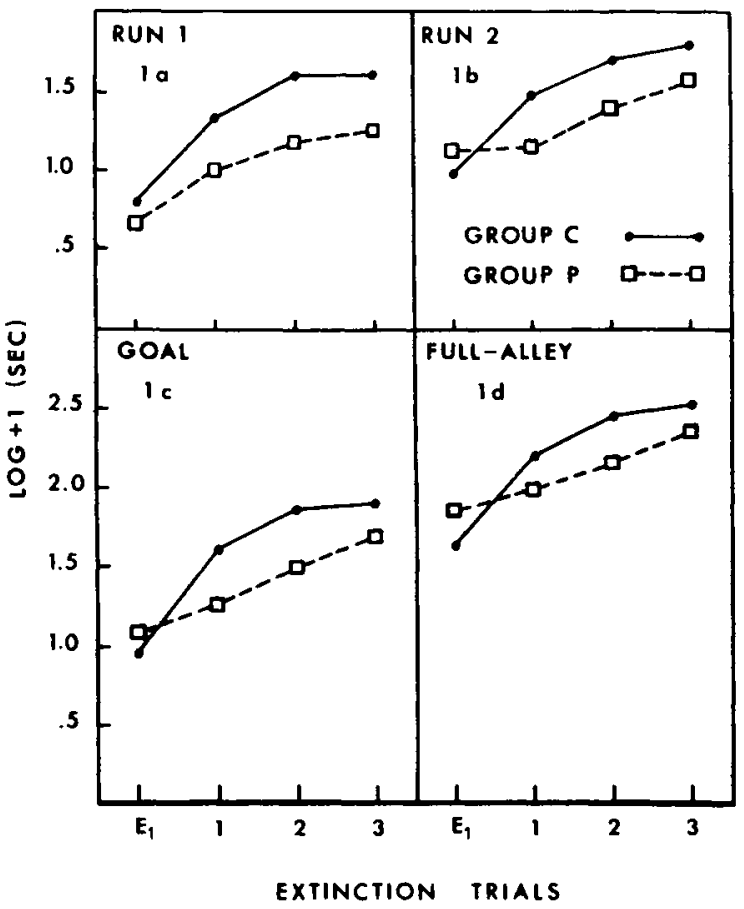

Fig. 1-a, -b, -c, \& -d. First extinction trial (E1) and means from blocks of three extinction trials for the four alley measures. 
than Group $\mathrm{C}$ and that this effect was not dependent on running speed during acquisition or at the beginning of extinction.

Although the results as regards extinction are quite clear in the present case, comparisons of groups given very small numbers of acquisition trials of ten present serious problems due to the high degree of individual variability. Several procedures have been considered. One which has become standard over the past few years is to drop Ss who fail to run on some specified number of acquisition trials. The use of various rate measures has been considered but this approach seems to create at least as many problems as it solves. A particular difficulty in rate measures is the determination of a base line. The approach that seems to offer the most promise is the use of the central part of the distribution of scores from each group. The basic rationale is that with severely limited experience in the training situation many Ss may be strongly influenced by irrelevant extraneous factors such as fear, any temporary sound, light, or other stimulus, or any minor error by the E. On a post hoc basis over 15 earlier studies which employed limited acquisition have been analyzed using the centered $60 \%$ of the scores (20\% of the scores from each end of each distribution were dropped). In no case was the order of results changed, but a number of differences were clarified. In the immediate future studies from this laboratory will be analyzed using both the entire distribution and the centered $60 \%$. At a later date primary emphasis will be placed on the centered $60 \%$ of the scores.

In the present study analysis of the centered $60 \%$ was carried out by eliminating two Ss from each end of each group distribution based on full-alley exttinction times. The remaining scores (Group $P=12$, Group $C=11$ ) gave the following results: With $\mathrm{df}=1 / 21$, Run $1, \mathrm{~F}=12.13, \mathrm{p}<.004$; Run 2, $F=12.90, p<.004 ;$ Goal, $F=9.77, \quad p<.006$, Full-alley, $\mathrm{F}=11.19, \mathrm{p}<.004$. As may be noted, there is a substantial change only in the Run 2 measure. The data in this study were more homogeneous than the usual study which employs a small number of trials but do illustrate the sort of results that might be expected from use of the centered $60 \%$ of the scores.

Results from the present study are obviously different from those of Amsel et al (1968). This does not necessarily mean that either the present study or Amsel's study are attributable to experimental error or artifact. There were substantial differences in procedure between the studies. One of the most obvious differences lies in the ITI. Amsel used a 24-h ITI while a 15-sec ITI was used in the present study. It is interesting to know that a PREE can be achieved with limited training and a long ITI. It may be the case, however, that with a long ITI the achievement of a PREE is more difficult. One method for overcoming such a difficulty would be the use of a large reward magnitude since large magnitudes tend to increase resistance to extinction in partial reinforcement groups and decrease resistance to extinction in consistent reinforcement groups. Logan (1960) reports obtaining effects similar to magnitude effects based on the number of pellets used with magnitude held constant. Similar results have been obtained by the present $E$ in two unpublished studies. There is also the work of Wolfe \& Kaplon (1941) using chickens. From these studies it seems reasonable to conclude that a number of pellets has an effect parallel to a larger magnitude of reward.
The "number" or magnitude effect may be important in producing a PREE with a small number of acquisition trials and a long ITI.

In addition to the study reported here, a more recent study in this laboratory has also obtained a PREE using a single 500-mg pellet and GB placement rather than running trials. Howlett \& Sheldon (1968), using a single 48-mg sugar pellet, found greater resistance to extinction following three partial delay trials as compared to three immediately reinforced trials. These three studies using a single pellet reinforcer have used massed trials. Whether similar results can be achieved with somewhat longer ITIs remains to be seen. In any case, a parsimonious explanation of the PREE would ideally cover both massed and spaced trials.

There are other results which would be difficult to explain even if multiple responses did account for the Amsel et al (1968) results. Particularly difficult are those studies in which only two acquisition trials were used (McCain, 1966, Experiment 2; McCain \& Brown, 1967). In the two-trial studies Ss explored alleys other than the test alley and had no previous experience with the test alley. The partial reinforcement groups received a single nonreinforced trial followed by a single reinforced trial. The consistent groups received two reinforced trials. The partial groups showed the typical PREE. The possibility of multiple reinforcements on a single trial was considered earlier (McCain, 1966, p. 265) but even if multiple responses were assumed the development of $F$ and $r_{f}-s_{f}$ are difficult to imagine in the two-trial situation. The sudden appearance of a frustration effect in the double alley (McCain \& McVean, 1967) raises similar questions for a threshold concept.

\section{REFERENCES}

AMSEL, A. The role of frustrative nonreward in noncontinuous reward situations. Psychological Bulletin, 1958, 55, 102-119.

AMSEL, A., HUG, J. J., \& SURRIDGE, C. T. Number of food pellets, goal approaches, and the partial reinforcement effect after minimal acquisition. Journal of Experimental Psychology, 1968, 77, 530-534.

CAPALDI, E. J., \& DEUTSCH, E. A. Effects of severely limiting acquisition training and pretraining on the partial reinforcement effect. Psychonomic Science, 1967, 9, 171-172.

HOWLETT, J. C., \& SHELDON, M. H. Effects of partial delay of reinforcement following a small number of acquisition trials. Psychonomic Science, 1968, 11, 259.

LOGAN, F. A. Incentive. New Haven: Yale University Press, 1960.

McCAIN, G. Partial reinforcement effects following a small number of acquisition trials. Psychonomic Monograph Supplements, 1966, 1, $251-270$.

McCAIN, G., \& BROWN, E. R. Partial reinforcement with a small number of trials: Two acquisition trials. Psychonomic Science, 1967, $7,265-266$

McCAIN, G., \& McVEAN, G. Effects of prior reinforcement or nonreinforcement on later performance in a double alley. Journal of Experimental Psychology, 1967, 73, 620-627.

PADILlA, A. M. A few acquisition trials: Effects of magnitude and percent reward. Psychonomic Science, 1967, 9, 241-242.

SPENCE, K. W., PLATT, J. R., \& MATSUMOTO, R. Intertrial reinforcement and the partial reinforcement effects as a function of number of training trials. Psychonomic Science, 1965, 3, 205-206.

SURRIDGE, C. T., RASHOTTE, M. E., \& AMSEL, A. Resistance to extinction of a running response after a small number of partially rewarded trials. Psychonomic Science, 1967, 7, 31-32.

WOLFE, J. B., \& KAPLON, M. D. Effect of amount of reward and consummative activity on learning in chickens. Journal of Comparative \& Physiological Psychology, 1941, 31, 353-361.

$$
\text { NOTE }
$$

1. This study was supported by NIMH Grant 14686-01. Thanks are due to Ronald T. Constant for extensive technical assistance. 